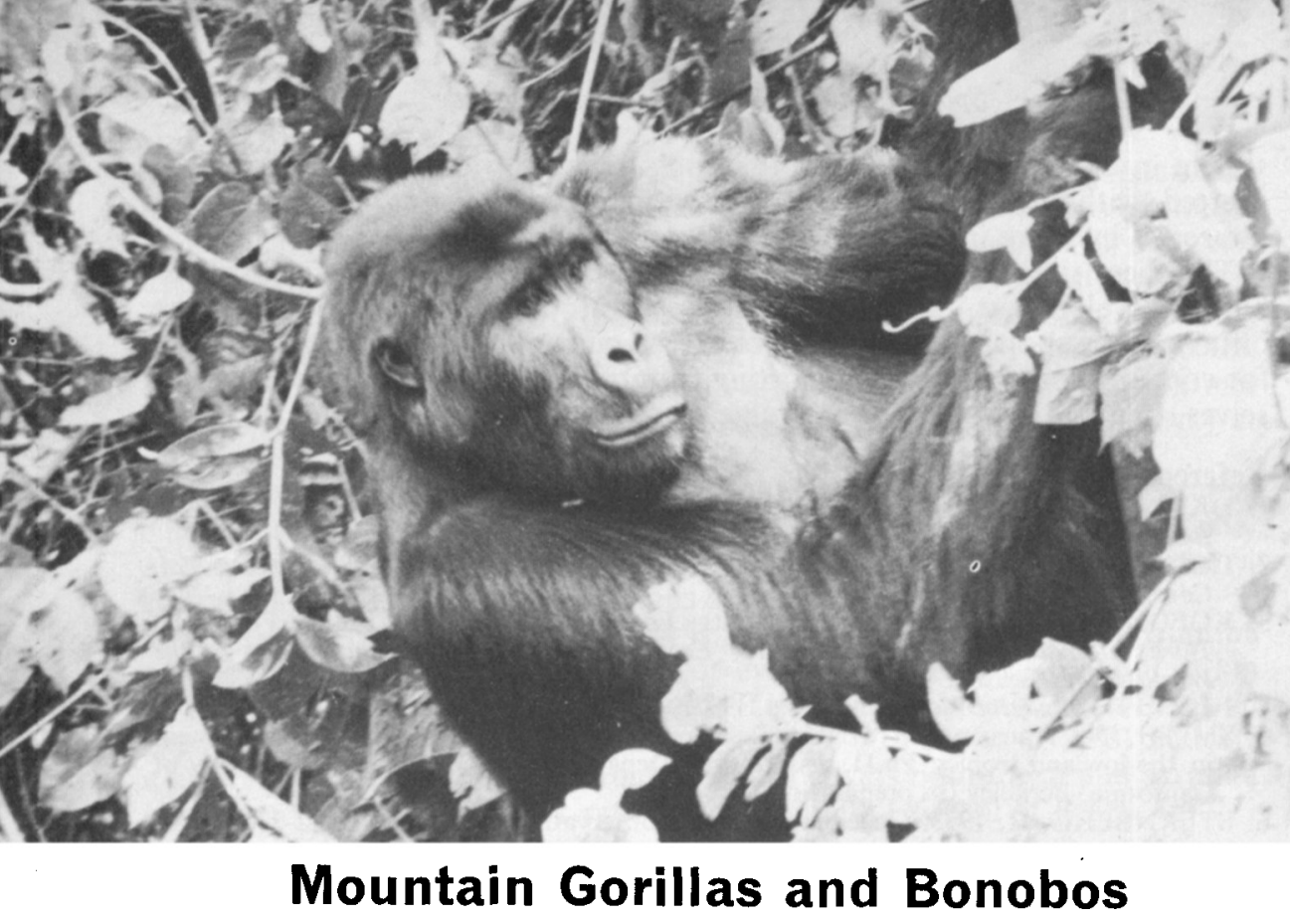

\title{
John Mackinnon
}

The author spent six weeks in Zaire early in 1975 to get first-hand experience both of mountain gorillas, in the Kahuzi Biega and Virunga national parks, and of bonobos (pygmy chimpanzees) in forests south of the Zaire river. As a result he believes that, for the mountain gorillas, the enlargement, already planned, of the Kahuzi Biega park is important to ensure that population's viability, and also that thought should be given to introducing new blood into the Virunga population, which may already be suffering from inbreeding. For the bonobos he suggests that, if investigation confirms the view that the Salonga National Park is not a good area for them, the Lomako-Bolombo region should be considered for a bonobo reserve. Dr Mackinnon is a member of the IUCN Survival Service Commission's Primate Group and has made major studies of the orang-utan.

The Kahuzi-Biega National Park is undoubtedly the best place in Zaire to see mountain gorillas Gorilla $g$. beringei, thanks to the remarkable efforts of one man, Adrien Deschryver, to protect them. Only 25 miles by road from the tourist town of Bukavu, the park covers 230 square miles on the slopes above the western shore of Lake Kivu, between 6500 and 11,000 feet. Starting in 1966 Deschryver, by regular visits, gradually habituated two gorilla families living along the eastern boundary of the reserve. Tourists can now be guaranteed a view of gorillas. Television and other publicity has enormously increased the flow of visitors, who are escorted by trained African staff into the forest to within a few yards of these impressive animals.

I spent five days watching and following one group of 21 animals led by the silver-backed male Mushamuka, and a further three days with a smaller 


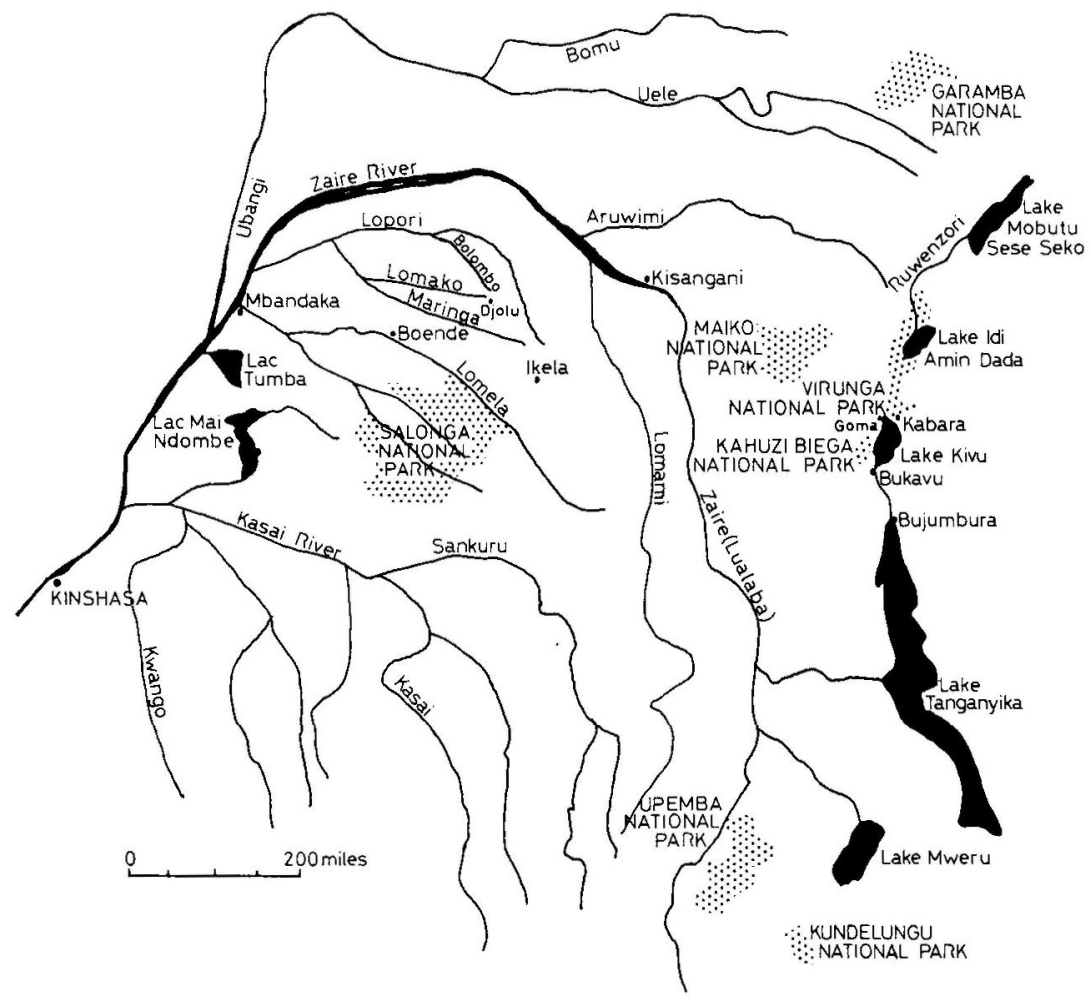

SKETCH MAP OF SADDLE AREA, KABARA, VIRUNGAS

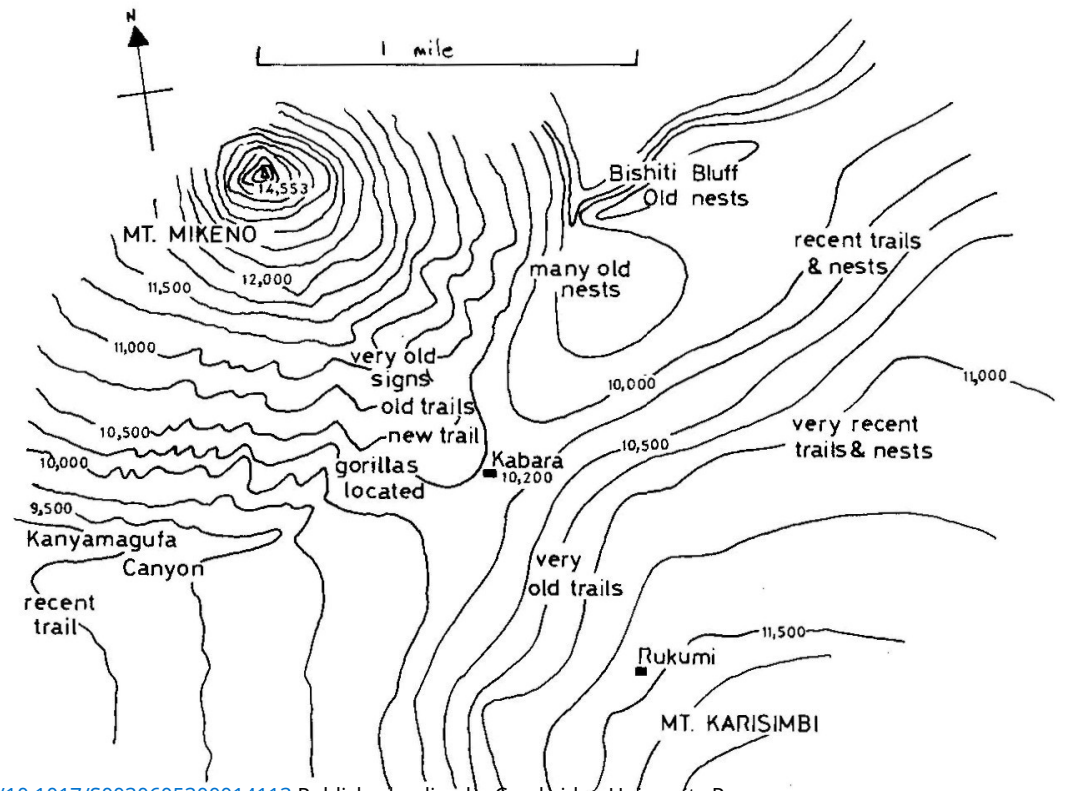


crude nests; on three days when it poured with rain they sheltered among the vine thickets at the base of trees, making snug rain bowers; on two days they continued their leisurely feeding throughout the midday. Youngsters used the midday halt to get together for play. In the afternoons the gorillas travelled more determinedly, feeding as they went, although on one afternoon they moved quite fast and barely ate anything. Daily ranging distance was about half-a-mile.

Perhaps the most famous locality for mountain gorillas is the Virunga Volcanos, where George Schaller carried out the bulk of his classic study and Dian Fossey and other field students have been studying them for the past eight years. This chain of five extinct peaks straddles the borders of Zaire, Rwanda and Uganda, the Zaire portion forming part of the enormous Parc National des Virungas (formerly Albert). For three days I stayed in the cabin at Kabara, 10,200 feet up on the saddle between Mt Mikeno and Mt Karisimbi, where Schaller had worked 14 years earlier. Both Kabara and Kahuzi Biega have a rainfall of about 70 inches, but otherwise these two gorilla habitats are very different. In Kahuzi-Biega gorillas live in the bamboo zone and the forest below; in the Virungas they are in the bamboo zone and the woodlands above. At Kahuzi-Biega the forest is a varied mosaic of some 25 tree species, the largest well over a hundred feet high; at Kabara there are only two main tree species and the highest barely reach sixty feet. The Kahuzi-Biega forest is hot and humid, whereas Kabara is bracing and night temperatures come close to freezing. But the two areas are similar in that the ground cover in both the Kahuzi-Biega secondary forest and the Virunga woodlands consists of a dense layer of tall herbs where gorillas find much of their food. Some plant species are common to both areas, but the Virunga herb layer seems more succulent and contains many genera of temperate climates, such as nettles, thistles, blackberries, docks, forget-me-nots, umbellifers and climbing bedstraw clingers.

We found traces of gorillas in the mixed Hagenia and bamboo forest below the saddle area at 9100 feet, extensive traces in the Hagenia and Hypericum woodland on the saddle area itself, and sparse traces up to 11,500 feet in the moorlands above the treeline and on the edge of the alpine zone, where the vegetation is characterised by Erica tree heathers, giant Lobelias and Senecios, Alchemilla and Helichrysum everlasting flowers. At Kabara we saw no gorillas, although we found several fresh tracks and on one occasion got very close to gorillas that screamed and moved off ahead of us. From following fresh trails we were able to deduce a good deal about the way the animals had travelled, fed, rested and nested over the past few days.

Compared with Kahuzi-Biega, very few sleeping nests were made off the ground and feeding signs indicated a comparatively monotonous diet of wild celery, vine skins, nettles, thistles and bedstraw clingers. Most signs were of small parties or lone animals, but we found fresh tracks of a group of at least 10 animals south of the Bishitsi bluff, and fresh tracks and nests of a group of at least 16 animals on the north-eastern slopes of Karisimbi.

These observations compare rather unfavourably with Schaller's findings ${ }^{10}$ when ten different groups totalling 169 animals used the saddle area around Kabara. Three days is obviously too short a time in which to make a proper census, but the population on the saddle today must be well below Schaller's figure. On the north-west Karisimbi slopes the only signs of gorillas were 
several months old, yet Schaller knew of two large groups that lived on these slopes. As there is no sign of habitat destruction the reduction in numbers is probably the result of increased human activity inside the park. We found many traces of poachers and dogs and also of cattle herdsmen on the saddle and on Karisimbi, and the fact that the only gorillas we came close to screamed and moved off is further indication that the population has become disturbed by man as in other parts of the Virunga chain. ${ }^{4}$ The only recent gorilla signs we found were all well off the main cattle and human trails.

\section{The Bonobo}

The bonobo is endemic in Zaire but it is widely distributed, inhabiting forested regions south and west of the Zaire and Lualaba rivers and north of the Kasai river, where over 80 per cent of the area is still forest. There are three categories of forest: secondary forests growing on cleared land, which are characterised by an abundance of such trees as Musanga smithii, Vernonia sp., Myrianthus sp., and on the ground gingers such as the common Afromomum; swamp forests which are permanently or seasonally flooded, with many trees over a hundred feet high forming a dense canopy; and primary forests on drier ground, which are the best formed forests, with trees up to $150 \mathrm{ft}$ and a great diversity of species, the tallest ones being mainly Leguminosae - Albizzia, Dialium, Scrodophloeus, Cynometra, Parkia and Pentaclethra spp. The bonobos utilise all three types of forest. Probably they were once common throughout the whole region; today they are absent from many areas and rare in others, apparently the result of increased human hunting. Only in a few scattered localities are they still regarded as common.

The bonobos range includes the Salonga National Park, at 12,000 square miles one of the largest parks in the world, and created to preserve rain forest and bonobos. Very remote and with no facilities, I could not visit it, but in 1972 a Japanese team found many signs of poachers and no signs of bonobos. ${ }^{6}$ Another supposed bonobo area is near Lac Tumba, ${ }^{9}$ but I saw no signs in the natural forest along the eastern shore. Most of the few reliable records from this area come from the forest to the south-west of the lake, which is largely swamp forest, but reports suggest that the bonobos only visit it during the dry season, when fruit is most abundant and they can travel on firm forest trails. ${ }^{9}$

Several encounters with large bands of bonobos $(10-30+)$ have been reported from the Djolu and Ikela areas, ${ }^{6}$ mostly in secondary forest where the wealth of ground vegetation provides good feeding. It is interesting that, like the mountain gorillas, bonobos seem to show a preference for artificially created secondary forests, but I was more interested in seeing them in the primary forests that must have been their natural habitat.

Between the Lomako and Bolombo rivers is a large and remote area of undisturbed primary forest where two young biologists, Noel and Alison Badrian, whom I visited, have been studying the bonobos for more than six months.* Both rivers are used by occasional fishermen and hunters using bows and arrows, but there are no permanent habitations. The area is a lush mosaic of both swamp and firm primary forests, and abounds in elephants, red forest hog Potamochoerus porcus, duikers, sitatungas, and especially in monkeys. Huge mixed troops of red-tailed monkeys Cercopithecus ascanius,

* An account by the Badrians of their bonobo study will appear in Oryx in November. 
guenons C. mona and mangabeys Cercocebus aterrimus were encountered many times a day, and small families of colobus monkeys Colobus angolensis were often close to the mixed groups though remaining apart. At ground level the forest was relatively open so that it was possible to travel without a machete. There were animal paths everywhere, the most complex web I have seen in a tropical forest. Every few yards there was a fork, and all the paths were padded hard by thousands of flat feet. The human path system in the forest south of the Lomako river, where I spent two days but where there were no signs of bonobos, was very simple in comparison to that north of the river, and I am forced to conclude that the bonobo is chiefly responsible for the maintenance of these paths. In the five days I was there we encountered bonobos four times and also found 46 sleeping nests and numerous feeding traces of these animals.

On the first encounter four animals (male, female, juvenile and 2nd stage infant) were feeding on fruit, resting, grooming and playing in the crown of a 100 -foot tree, and we watched them unnoticed for over an hour. They travelled through two more trees before the leading female climbed down. But when nearly on the ground she saw us, climbed hurriedly back up into the canopy, giving loud, high-pitched, rather eerie screams similar to a herring gull's calls, and, with her clinging infant, led the flight through the tree-tops. I was greatly impressed by her speed and agility at great height, but I was able to keep her under observation by following her movements on the ground. She was unwilling to descend while I was close, but when I stopped following she went on for a short distance before climbing down and fleeing silently on the ground. The two other animals passed overhead and followed her.

On the second encounter three animals (male, female, and juvenile) were observed in the early morning feeding on the ripe red fruits of a large tree Antiaris welwitschii. After about fifteen minutes, although we were about 80 metres away and well concealed by undergrowth, the bonobos spotted us, hurried down to the gound and vanished without a sound.

The third and fourth encounters occurred when we heard bonobo screams both ahead of us and to our right, the same noise as had been directed at us in the first encounter. The calls to our right got closer, and while we were deliberating which to follow, we saw a large male approaching fast on the ground from the right in a quadrupedal fashion. Immediately he saw us and ran back the way he had come. From the calls we had heard we thought there were other animals with him. The calls ahead of us continued, and we approached to find a single juvenile female sitting about twenty feet off the ground, displaying, shaking vines and screaming, her attention focused on the ground under the tree. Possibly she had seen a snake or some other frightening creature and was afraid to descend; it seemed that her screams had attracted another nearby party who had hurried towards her. After a few minutes she became aware of our presence and directed her display almost unchanged towards us. When we approached closer she hurried back through the trees, slipped to the ground and disappeared.

All encounters were with small parties (1-4 animals). The Badrians have made over sixty additional encounters with bonobos in this area and all but one of these have been with small parties. This is in marked contrast with the large parties reported for other areas. ${ }^{6}$ Possibly large parties are adaptive in secondary forest where, in the absence of baboons, they are able to occupy a 
baboon-like niche; larger bands may also be possible in the fruit season when food is more abundant. In the forest $I$ examined fruit was scarce and dispersed, as is typical for a tropical rain-forest, and small parties must be more successful at finding food under such conditions.

The construction of the tree sleeping nests was indistinguishable from that of common chimpanzees and nests were of a similar size. I was, however, surprised at their height. The mean height of 46 nests seen was 82 feet (S.D. $=22.2$ ). This is much higher than those of common chimpanzees in any locality, or even than those of orang-utans, whose mean height in the Ulu Segama, in Borneo, was only 65 feet. $^{8}$

In the forest nest distribution was far from even. Most of the nests in this sample were found in three separate clusters, in each case in the immediate vicinity of a single large fruit tree-twice Antiaris welwitschii, and once Parinari excelsa. This orientation to fruit trees enables us to deduce something about their daily ranging habits. A cluster of green nests close to a single fruit tree might suggest that a large band of bonobos had visited the tree once, but we were able to observe how the number of nests around the first Antiaris tree increased gradually over a few days, the results of several visits by only one or two small groups. The nests around the Parinari tree were similarly the results of several visits; the previous month the Badrians had observed the bonobos feeding there several times.

The first Antiaris tree was richly covered in sweet red fruit and was obviously being visited regularly by bonobos. Unfortunately it was two hours' journey and although we visited the tree on four mornings and found new nests on each occasion, we were only once there early enough to see the bonobos; twice they must have arrived after 16.00 hours when we left the tree. It thus appears to be fairly standard behaviour for bonobos to return in the evening to the best nearby fruit tree for their last meal of the day, nest close by, and feed again in the morning before setting off on a long forage for other types of food.

We found many fresh food traces along the bonobo trails. These were mostly the bitten-off shoots of the common climbing cane Haumania librechtsiana and the curled white-sheathed leaves of Sarcophrynium machrostachym, which is eaten locally by humans. The animals had not left the trails to go into the bush on either side to collect more shoots, nor were there anywhere signs of a large meal of these shoots. Rather we would find one stalk here and two more further along the trail. It looked as though animals ate them incidentally as they travelled, indeed some of the stalks were found several yards from the nearest live plant.

I was greatly struck by the parallel with the orang-utans' use of the climbing bamboo Dinochloa pubiramea, one of the commonest plants in the Bornean forest of the Ulu Segama region. Both Dinochloa and Haumania are cane forming, monocotyledon climbers that form dense thickets wherever there is a break in the canopy and sunlight reaches the forest floor. Both plants are the most frequently eaten food-species of orang-utan and bonobo respectively in these areas, not because they are especially favoured but because they are so abundant, a supplementary filler that is always available.

The bonobo clearly exploits two quite separate forest strata, the ground layer and the crowns of the large fruit trees. There is no primate competition on the ground. No baboons, drills, mandrills, common chimpanzees or 
Table 1

Lomako,

Zaire

Segama, Borneo

Tree densities per hectare

$$
\begin{gathered}
25-49 \mathrm{ft} \\
178
\end{gathered}
$$

250
$50-74 \mathrm{ft}$
78

78

148

$75-99 \mathrm{ft}$
62

63

$\begin{array}{cc}100+\mathrm{ft} & \text { Total } \\ 98 & 416 \\ 52 & 510\end{array}$

gorillas have ever become established in the central Congo basin. In the canopy the bonobo is adapted to exploit the large fruiting trees in a way that resident monkeys cannot do. The greater mobility of the ground-travelling bonobos enables them to search out the large but dispersed, rich food sources. Because monkeys are limited to much smaller territories they rarely have the chance to feed at such sites, and because of their small size are less able to take advantage of fruit abundances when these do occur.

There seems to be some tendency for bonobos to use these two strata at different times of day, feeding in the canopy layers in the morning and evening and on the shaded ground through the middle of the day when the canopy layers become very hot and dry. This is similar to the midday shift in stratum use that has been demonstrated for Malayan siamangs. ${ }^{3}$

\section{Chimpanzee Comparison}

The enormous Zaire river is a major geographical barrier for primates, so it is not surprising to find a distinct species of chimpanzee on the south side. Almost all the primates south of the river are distinct at specific or subspecific level from their relatives on the north side. ${ }^{11}$ As chimpanzees are wide-ranging and relatively promiscuous, there must always have been fast gene flow throughout their distribution from Senegal to East Africa which would prevent populations becoming closely adapted to any particular habitat. Instead, we find very much the same, adaptable, robust chimpanzee occupying such different habitats as dry savanna, deciduous and montane forests, open woodlands and rain forest. Genetically isolated on the south side of the Zaire river, the bonobo has been able to specialise into a purely rain-forest species, and the main structural and behavioural differences between the bonobo and the common chimpanzee are direct results of this specialisation.

The precise structure of the African rain forest has been of enormous importance in moulding the bonobo's evolution. A comparison of the structure of African and Asian rain forest helps us to understand the differences between the bonobo and the Asian apes. Using a telephoto lens as range finder I counted and measured trees in a sample plot 6 metres wide along 425 metres of trail in the Lomako area. The sample comprised 106 trees of over 25 feet, equivalent to 416 trees per hectare. Table 1 gives the frequency per hectare of trees in different height categories together with comparable figures for a typical Bornean forest where orang-utans and gibbons occur. The Bornean forest contains the tallest trees in either sample, but it can be seen that the Lomako sample contains far more trees that exceed 100 feet. The African rain forest has a thicker and more continuous upper canopy than that found in south-east Asia and a consequently thinner middle storey.

In South-east Asia the orang-utan travels primarily through the middle storey of the forest in a slow quadrumanual fashion, transferring from one 
small tree to the next. The scarcity of trees in this height range precludes such locomotion for bonobos, and also explains the greater height of their nests. The bonobo is forced to travel either along the ground or high in the upper canopy, and usually chooses to travel along the ground as a knuckle-walker, like the gorilla and common chimpanzee, this being cheaper energetically, quicker and quieter than arboreal travel. If threatened by terrestrial predators, or moving through flooded swamp forest, however, the bonobo must be able to use the treetop route, and certainly exhibits greater agility and assurance in the high canopy than the common chimpanzee, thanks largely to its smaller size and more slender build. In this respect the bonobo shows convergence with the small hylobatid apes of Asia that habitually travel through the upper canopy.

Bonobo society appears to be loose and open as in common chimpanzee and orang-utan populations, but there is a striking difference with common chimpanzees in the frequency and variety of calls. Common chimpanzees use an elaborately differentiated series of vocal barks, grunts and screams for communication both within and between different foraging parties. A chimpanzee forest echoes with these loud calls, and no visitor can remain ignorant of the presence of chimpanzees for long. The bonobo, however, is a quiet animal and appears to have neither long-range contact calls nor territorial calls, and shows little excitement when different small parties meet at fruit trees (Badrian, pers. comm.). Their only loud vocalisation is the highpitched alarm scream when they see humans or dogs, which attracted us to our third and fourth encounters, but is rarely heard in any other context. This small repertoire compared with the common chimpanzee is entirely consistent with their rain-forest habitat, and convergent with the low level of vocalisation between and within foraging parties of orang-utans.

\section{Conservation of Zaire's Apes}

The interest shown in wildlife conservation by the Zaire government and the President himself is very heartening. Zaire is a country of enormous and diverse natural wealth, with much that is worth preserving, as Jacques Verschuren showed in two articles in Oryx last year. The National Institute for the Conservation of Nature has shown great foresight in expanding the system of national parks. The seven now open cover about 20 per cent of the country, and more are planned. The Parc des Virungas must be rated as one of the most superb parks in the world, and Kahuzi Biega is effective, giving good protection to its wildlife while offering excellent opportunities for both casual visitors and serious research. In other parks facilities are less good, but as these improve more visitors will make use of them, bringing important foreign revenue.

The future of conservation in Zaire looks encouraging but it does seem pertinent to make some suggestions with particular reference to gorillas and bonobos:

1. The Kahuzi-Biega park should be enlarged as planned so that it includes sufficient gorillas for long-term viability of the population.

2. Some authors ${ }^{5}$ recognise two different subspecies of eastern gorillas: a mountain gorilla $G$. g. beringei, including the Virunga, Kahuzi-Biega and Ugandan populations, and an eastern lowland gorilla G. g. graueri, including all other gorilla populations in eastern Zaire. Whether accepted or not, 
we must appreciate that different gorilla populations show different morphological and behavioral adaptations to their respective habitats, and at least one large area of lowland habitat should be preserved to ensure the survival of eastern lowland gorillas. Possibly the Maiko National Park will suffice but other areas are worth investigating.

3. The survival of the Virunga population of gorillas requires a check on further agricultural encroachment and planning. The problem on the Zaire side is less acute than on the Rwandan and Ugandan sides, but we did encounter poachers at Kabara. The trouble is that too few visitors presently stay at Kabara to make the continuous presence of game rangers worthwhile. Large numbers of tourists climb the active volcano Nyiragongo, and I am sure that equal numbers would visit Kabara and Rukumi if the gorillas were more approachable. Apart from the gorillas the alpine scenery is breathtaking. Perhaps a first step in this direction would be to encourage a research student to use Kabara for another field study of gorillas. This would result in the clearance of poachers from the Mikeno-Karisimbi saddle and the rehabituation of the gorilla groups to peaceful observers.

4. Another serious consideration is the possibility that the Virunga population is already too small for long term genetic viability and suffers from inbreeding. This is very probable, and serious thought should be given to the idea of introducing new blood into the Virunga population in the form of occasional lone animals removed from the Kahuzi Biega National Park. The argument that we should maintain the 'purity' of the Virunga population is not really valid as the isolation of this population is only very recent and probably artificial.

Until recent times the distribution of gorillas was limited by the western rift valley. Only when the Virunga lava flow formed a forested dam across the rift, less than 9000 years ago, ${ }^{7,1}$ could gorillas extend their range to include the Virunga volcanos and thence the Impenetrable Forest of Uganda. Probably the Virunga population could never have been maintained without regular genetic exchange with the populations west of Lake Kivu and in Uganda. Such genetic exchange has only been broken in the last 300 years by artificial forest clearance. The restoration of limited genetic exchange between these populations may be crucial to the survival of the gorillas on the volcanos.

5. The little information presently available suggests that the Salonga National Park is not ideally placed as a reserve for bonobos. If subsequent inquiry confirms this view, I strongly recommend that the Lomako-Bolombo region be considered as a park for this species. The area is undisturbed primary forest habitat, containing many bonobos and a wealth of other wildlife. The clear river boundaries make it an easy area to patrol, and there are no permanent human settlements within the area that would be displaced.

\section{Acknowledgments}

I would like to acknowledge the help of the late Miss Lee Lyon, and to thank $\mathrm{Mr}$ Mushenzi Lusenge, Adrien Deschryver, Jean Pierre von der Becke and Noel and Alison Badrian for their assistance in facilitating my visits to gorilla and bonobo habitats, and to thank Mr and Mrs Sperlocke and Mr and Mrs Chill of Bukavu, Père Paul of Boende, Steve Bozarth of Bikoro, Luc Larose of Befali, and M. Christiaens of Bokoli for their hospitality. 


\section{References}

1. BUTZER, K.W., ISAAC, G.L., RICHARDSON, J.L. \& WASHBOURN-KAMAU, C. 1972. Radiocarbon dating of East African lake levels. Science, 175: 1069-1076.

2. CASIMIR, M.J. \& BUTENANDT, E. 1973. Migration and core area shifting in relation to some ecological factors in a mountain gorilla group (Gorilla gorilla beringei) in the Mt. Kahuzi Region (Republique du Zaïre). Z. Tierpsychol., 33: 514-522.

3. CHIVERS, D.J. 1974. The Siamang in Malaya. Contributions to Primatology No. 4, S. Karger.

4. GROOM, A.F.G. 1973. Squeezing out the mountain gorilla. Oryx, 12: 207-215.

5. GROVES, C.P. 1970. Population systematics of the gorilla. J. Zool., London, 161: $287-300$.

6. KANO, T. 1974. A Pilot Study on the Ecology of Pygmy Chimpanzee Pan paniscus. Unpublished report.

7. KORTLANDT, A. 1972. New Perspectives on Ape and Human Evolution. Stichting voor Psychobiologie.

8. MACKINNON, J. 1971. The orang-utan in Sabah today. Oryx, 11: 141-191.

9. NISHIDA, T. 1972. Preliminary information on the pygmy chimpanzee Pan paniscus of the Congo Basin. Primates, 13(4): 415-425.

10. SCHALLER, G.B. 1963. The Mountain Gorilla, Ecology and Behaviour. Chicago.

11. SCHOUTEDEN, H. 1947. De Zoogdieren van Belgisch Congo en van RuandaUrundi.

Dr MacKinnon is at the Sub-Department of Veterinary Anatomy, Tennis Court Road, Cambridge CB2 1QS.

\section{Planning a World-wide Park System}

The Distribution of Protected Areas in Relation to the Needs of Biotic Community Conservation in Eastern Africa by Hugh F. Lamprey (IUCN Occasional Paper 16), is the fruit of IUCN's programme to ensure a world-wide system of national parks and protected areas to conserve representative samples of natural biomes and ecosystems. Dr Lamprey points out that in the past indigenous ecosystems have survived usually by accident or because serious obstacles had not been developed, or to protect an individual species. But there has never been a plan to ensure that no habitat type is irretrievably lost. In East Africa, for example, the only breeding sites of the lesser flamingo (Lake Natron and Lake Rudolf) are not protected, neither is any dugong habitat on the Kenya coast.

The need for speed is obvious - with human pressures constantly expanding into hitherto undeveloped areas. National park or nature reserve status does not guarantee protection - enforcement being nearly as important and often more difficult - but it is the vital first step. His check-list of biotic communities covers nine countries - Kenya, Tanzania, Uganda, Ethiopia, Somalia, Sudan, Malawi, Zambia and Botswana, with a map for each. From these he extracts 24 biomes and sub types that are recommended for protection, with detailed suggestions.

\section{Why Destroy Moles?}

Destroying moles is the sort of traditional activity that continues in Britain without any real thought being given to the reason, or its necessity being questioned. Professor Kenneth Mellanby, speaking to the RSPCA Wild Animals Committee, described trapping as both ineffective and cruel, and poisoning as the only effective way to get rid of moles and that means strychnine. But he doubted whether moles were worth the trouble of controlling at all; in Huntingdonshire he found that most farmers ignored moles. The number of molehills varies with the fertility of the soil. Where it is good the moles have an easy life, do little digging and achieve a stable population of about two per acre, and surplus moles migrate. In poor soils they have to work much harder to find the worms they need and molehills are numerous. On arable land moles are not a serious problem; it is only on grass that is to be cut for hay that their activities are harmful. 